Article

\title{
Experimental Research of the Heat Storage Performance of a Magnesium Nitrate Hexahydrate-Based Phase Change Material for Building Heating
}

\author{
Yang $\mathrm{Li}^{1,2}$, Caixia Wang ${ }^{2}$, Jun Zong ${ }^{2}$, Jien $\mathrm{Ma}^{1, *}$ and Youtong Fang ${ }^{1}$ \\ 1 Department of Electrical Engineering, Zhejiang University, Hangzhou 310027, China; \\ liyang83901998@163.com (Y.L.); youtong@zju.edu.cn (Y.F.) \\ 2 New Energy Technology Research Institute, State Power Investment Corporation Research Institute, \\ Beijing 102209, China; wangcaixia@spic.com.cn (C.W.); zongjun@spic.com.cn (J.Z.) \\ * Correspondence: majien@zju.edu.cn; Tel.: +86-137-5716-1686
}

check for updates

Citation: Li, Y.; Wang, C.; Zong, J.; Ma, J.; Fang, Y. Experimental Research of the Heat Storage Performance of a Magnesium Nitrate Hexahydrate-Based Phase Change Material for Building Heating. Energies 2021, 14, 7108. https:// doi.org/10.3390/en14217108

Academic Editors: Andrea Frazzica and Adrián Mota Babiloni

Received: 2 September 2021

Accepted: 19 October 2021

Published: 1 November 2021

Publisher's Note: MDPI stays neutral with regard to jurisdictional claims in published maps and institutional affiliations.

Copyright: (c) 2021 by the authors. Licensee MDPI, Basel, Switzerland. This article is an open access article distributed under the terms and conditions of the Creative Commons Attribution (CC BY) license (https:// creativecommons.org/licenses/by/ $4.0 /)$.

\begin{abstract}
Phase change heat storage material is a preferred material in solar building heating or off-peak electric-heat storage heating technology and is the research focus. A compact phase change thermal storage device has been designed and experimentally studied for improving heating system load in this work. A new type, magnesium nitrate hexahydrate-based phase change material has been studied to improve the cooling degree and crystallization difficulty. The focus of this study is on the heat charging and discharging characteristics of this new phase change material. The heat storage device has two groups of coils, the inner side which carries water and the outer side which is the phase change material. A testing system was built up to value the thermal cycling performance of the heat storage device. The measurement data include phase change material temperature field, water inlet and water outlet mean temperature, heat charging and heat discharging depth, and flow rates over the operating period. The results show the phase change material has a quick response with the operating temperature range of $20-99{ }^{\circ} \mathrm{C}$. Its latent heat is $151.3 \mathrm{~J} / \mathrm{g}$ at $91.8^{\circ} \mathrm{C}$. The heat storage density of this phase change material is about $420 \mathrm{MJ} / \mathrm{m}^{3}$. The thermal performance degradation is about $1.8 \%$ after 800 operation cycles. The phase change thermal storage device shows flexibility and a great potential to improve the capacity and economy of heating systems.
\end{abstract}

Keywords: heat storage performance; phase change material; heat storage; building heating; magnesium nitrate hexahydrate

\section{Introduction}

Ecological environment and energy utilization are closely related to social health development [1,2], and more than ninety percent of the world energy budget is connected to heat conversion and storage [3]. Due to its wide applicability, heat storage has attracted more and more attention in renewable energy power generation, solar building heating, and power grid peak shaving [4,5]. Different from other existing energy storage, heat storage has significantly high stability and low cost [6,7]. Especially in recent years, responding to the nationwide policy of "coal to clean energy", solar heating and electric heating is increasingly used in northern China to reduce coal-fired heating and its resulting pollution emissions [8,9]. This brings significant market prospects for heat storage technology to fill the energy demand gap economically. Phase change heat storage materials are different from common sensible heat storage materials [10]. Because of their latent heat, phase change materials (PCMs) can store additional energy at a certain temperature [11]. This allows them to play important roles in improving energy storage cost and balancing the mismatch between heating supply and demand [12]. The PCMs used in special fields should have certain thermophysical properties. For instant requirement such as building heating, the PCMs should have better thermal conductivities to get quick response, and 
the phase change temperature of the PCMs should be between 40 and $90^{\circ} \mathrm{C}$. PCMs include organic and inorganic materials [13]. The organic PCMs include fatty acids and paraffin wax, most of them have relatively stable chemical properties. However, these organic PCMs are always expensive and burn easily, and present poor thermal conductivity. The inorganic PCMs usually include salts, salt hydrates, and eutectic. Unlike organic materials, inorganic compounds are generally cheap and nonflammable, and have better thermal conductivity performance and higher density, all of these are helpful to obtain high heat storage performance. However, so far, most of the PCM used in buildings are organic materials. Inorganic PCMs lack application due to the problems such as supercooling and unstable circulation caused by phase separation [14]. Supercooling brings extra cooling capacity to release latent heat, and phase separation may lead to the failure of inorganic hydrate to maintain its phase change characteristics in long-term thermal cycle. Because the temperature of building heating is usually below $100^{\circ} \mathrm{C}$, it is valuable to study hydrated salt PCMs. Through comparison and selection, magnesium nitrate hexahydrate (MNH) with phase change temperature close to $89^{\circ} \mathrm{C}$ and latent heat about $162 \mathrm{~J} / \mathrm{g}$ is more suitable for this temperature range, and it has relatively higher chemical stability, lower corrosivity, and better economy. There are also cycle stability and supercooling problems in pure $\mathrm{MNH}$. In order to solve the supercooling problem of pure MNH, Lane et al. [15] selected a variety of isomorphic additives as candidate nucleating agents, and freezing experiments show that the addition of $0.5 \mathrm{wt} \%$ sulfate hydrate can greatly inhibit the supercooling of pure MNH. Wang $\mathrm{H}$ et al. [16] proposed to prepare composite PCMs by combining photo-thermal materials. Solar-driven composite PCMs can absorb photons and convert them into thermal energy, most of which are stored in PCMs in the form of latent heat. The driving energy of PCMs comes from solar energy or other heat sources. First, a new solar-driven composite PCM containing $\mathrm{MNH}$, carboxymethyl cellulose, and graphene was prepared, and its absorption capacity and photo to heat storage properties were measured by full spectrum system. Compared with pure $\mathrm{MNH}$, the adsorption capacity of graphene composites increased from $46.54 \%$ to $79.12 \%$. The photo to heat conversion and storage efficiency of composite PCMs can reach $69.73 \%$, while pure $\mathrm{MNH}$ is not enough to absorb a large amount of latent heat because of its low absorption capacity. The thermal conductivity of the composite PCM with 5\% graphene increased by $191.18 \%$.

Zhang MH et al. [17] systematically studied the kinetic characteristics and its behavior of multi-step thermal decomposition of MNH. The results show that the pyrolysis of $\mathrm{MNH}$ is a complex multi-step reaction. It includes three reaction processes. The first two reaction processes are characterized by the precipitation of $\mathrm{H}_{2} \mathrm{O}$, while the third reaction process is characterized by the precipitation of $\mathrm{NO}_{2}$. The order of the three processes is diffusion, orderly nucleation, and growth mechanism. Neeraj et al. [18] experimentally studied the effects of carbon materials of different sizes and shapes on the thermophysical properties of $\mathrm{MNH}$. The experimental results show that the thermal conductivity of $\mathrm{MNH}$ can be increased by $100 \%$ by adding $0.5 \mathrm{wt} . \%$ carbon spheres. The results of differential scanning calorimetry show that the addition of carbon material improves the phase change and reduces the supercooling effect without affecting the latent heat capacity of the material. Honcova et al. [19] tried to reduce the supercooling of pure $\mathrm{MNH}$ by adding some additives, the mass fractions is from 0.5 to $2 \%$. DSC results show that $\mathrm{Mg}(\mathrm{OH})_{2}$ is very effective which can reduce the supercooling of pure MNH by about $90 \%$. Honcova P. et al. [20] carried out a study on the thermal stability of MNH by adding carbon nanomaterials. The results show that graphite and graphene provide the highest energy, and the supercooling inhibition decreases from about $30 \mathrm{~K}$ to $2.2 \mathrm{~K}$ in 50 cycles. The addition of $3 \%$ graphite and $3 \%$ graphene can significantly increase $9 \%$ and $15 \%$, respectively. Nagano et al. [21] also studied the corrosivity of MNH to metals such as aluminum and steel. The experimental results show that aluminum has good corrosion resistance to $\mathrm{MNH}$, but carbon steel is not suitable. The experimental results show that the aluminum container can maintain the storage performance of $\mathrm{MNH}$ and its modified composites even after 1000 charge-discharge cycles. Li TX et al. [22-24] developed a modified MNH composite containing a certain 
amount of nucleating agent for low-cost energy storage applications at medium and low temperatures. The results show that the supercooling of the composites can be maintained at about $2 \mathrm{~K}$ during solidification. So far, the research on the thermophysical properties modification and cycle performance evaluation of $\mathrm{MNH}$ including the modified composites with $\mathrm{MNH}$ as the main material all basically proved the applicability of MNH in medium and low temperature energy storage. However, for the large area application potential of $\mathrm{MNH}$, such as industrial waste heat recovery and the use of "peak valley electricity price" for thermal regulation of electric building heating, there still are uncertainties. At present, the research on thermal design and performance evaluation of actual scale storage equipment using this material is quite few. In addition, some important results obtained in previous studies, such as the theoretical heat storage capacity and supercooling of materials, heat charging and heat discharging performance, need to be further analyzed and evaluated in practical application. In this work, the main thermal properties and supercooling stability of the modified MNH named as MNH90 were characterized. After confirming that the material can be recycled, we designed and manufactured a small latent heat storage device for the phase change material, and tested the charging and discharging performance of the energy storage device under certain working conditions with the electric boiler as the heat source and the cold water tank as the cold source. Some suggestions for thermal design and operation of the equipment are also put forward in the end of this work. The purpose of this paper is to prove the potential of MNH90 in the field of medium and low temperature heat storage and building heating.

\section{Experimental Set Up}

\subsection{Phase Change Material}

The thermal-physical properties of the MNH90 include latent heat, melting point and specific heat were measured by using a differential scanning calorimeter (DSC214, NETZSCH-Gerätebau $\mathrm{GmbH}$ ). Figure 1 shows the specific heat of phase change material MNH90. The mass of sample analyzed here is about $20.75 \mathrm{mg}$. Concavus aluminum crucibles were used to fix samples in the DSC. The operating temperature range for these experiments was from 20 to $120^{\circ} \mathrm{C}$, the heating rate of the measurement was set to $1 \mathrm{~K} / \mathrm{min}$, and the flow rate of purge nitrogen and protective nitrogen is set at $40 \mathrm{~mL} / \mathrm{min}$ and $60 \mathrm{~mL} / \mathrm{min}$, respectively. Sapphire is taken as the standard sample, and its mass is $20.75 \mathrm{mg}$. It can be seen from the results that the specific heat of $\mathrm{MNH} 90$ is $1.6 \mathrm{~J} /(\mathrm{g} \cdot \mathrm{K})$ at $20^{\circ} \mathrm{C}$. The specific heat increases slowly with the increase of working temperature. The specific heat reaches $4.1 \mathrm{~J} /(\mathrm{g} \cdot \mathrm{K})$ at $120^{\circ} \mathrm{C}$.

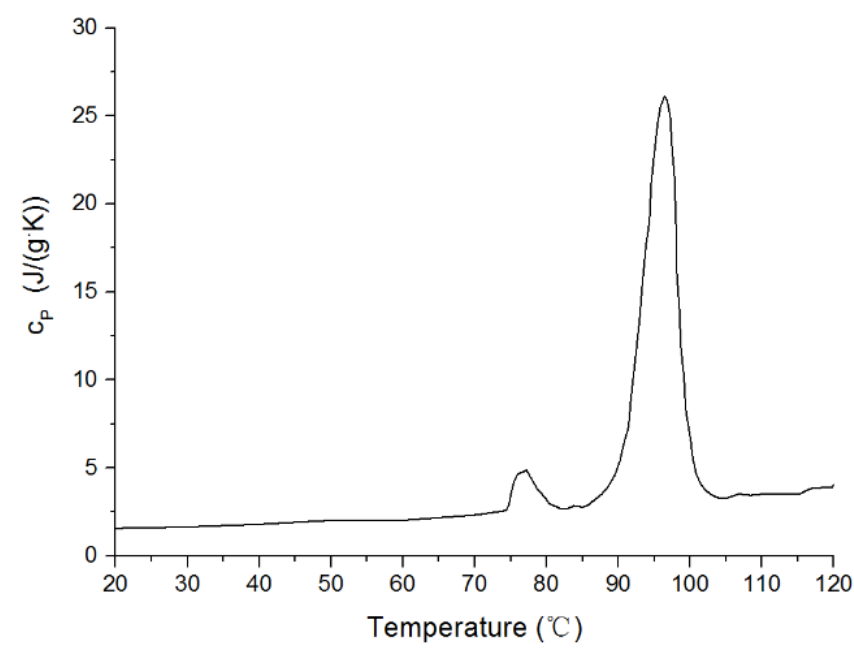

Figure 1. Specific heat capacity of phase change material MNH90.

The mass of MNH90 sample to be analyzed for latent heat is about $16.51 \mathrm{mg}$. Heat the sample from $20^{\circ} \mathrm{C}$ to $110^{\circ} \mathrm{C}$ and then cool it to $20^{\circ} \mathrm{C}$, the heating rate was set to 
$1 \mathrm{~K} / \mathrm{min}$, and the flow rate of purge nitrogen and protective nitrogen is set at $40 \mathrm{~mL} / \mathrm{min}$ and $60 \mathrm{~mL} / \mathrm{min}$, respectively. Figure 2 reveals that in the heating stage, MNH90 has two endothermic peaks corresponding to $74.4{ }^{\circ} \mathrm{C}$ and $94.3^{\circ} \mathrm{C}$. The melting point corresponding to the larger peak is around $91.8^{\circ} \mathrm{C}$, so the melting point of the material is $92{ }^{\circ} \mathrm{C}$, the latent heat is about $151.3 \mathrm{~J} / \mathrm{g}$, and in the cooling stage, the solidification temperature of the material is about $68{ }^{\circ} \mathrm{C}$. Compared with pure $\mathrm{MNH}$, due to the addition of $0.3 \mathrm{wt} \%$ nanoparticles and $2 \mathrm{wt} \%$ additive $\mathrm{A}$, the supercooling degree and the stability of charging and discharging of MNH90 have been greatly improved, and the density, thermal conductivity, and specific heat of MNH90 are also higher than pure MNH. However, these nanoparticles and additive A do not have the ability to store latent heat in this operating temperature range, resulting in the latent heat of MNH90 to decrease slightly than that of pure $\mathrm{MNH}$. According to the results, the $\mathrm{MNH} 90$ material can be used for heat storage and building heating system, which can meet the user's demand of $60{ }^{\circ} \mathrm{C}$ heating/hot water consumption. It can be estimated that the heat storage density of MNH90 is about $420 \mathrm{MJ} / \mathrm{m}^{3}$, which is about 2.5 times than that of water, assuming the heat storage working temperature range is $40^{\circ} \mathrm{C}$. The thermal properties for $\mathrm{MNH}$ and $\mathrm{MNH} 90$ are provided in Table 1.

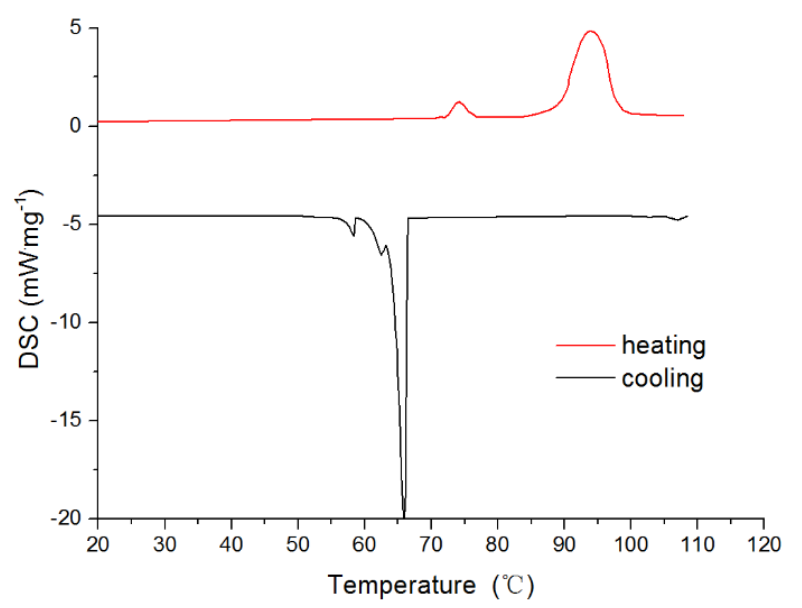

Figure 2. DSC curve of phase change material MNH90.

Table 1. Thermal properties for MNH and MNH90.

\begin{tabular}{cccccc}
\hline Material & $\begin{array}{c}\mathrm{T}_{\mathrm{m}} \\
\left({ }^{\circ} \mathbf{C}\right)\end{array}$ & $\begin{array}{c}\Delta \mathbf{H}_{\mathbf{m}} \\
(\mathbf{J} / \mathbf{g})\end{array}$ & $\begin{array}{c}\boldsymbol{\rho} \\
(\mathbf{g} / \mathbf{m})\end{array}$ & $\begin{array}{c}\mathrm{C}_{\mathbf{P}} \\
{[\mathbf{J} /(\text { gial) })}\end{array}$ & $\begin{array}{c}\lambda \\
{[\mathbf{W} /(\mathbf{m i a l})]}\end{array}$ \\
\hline Pure MNH & 89.9 & 162.8 & 1.636 & 1.8 & 0.67 \\
MNH90 & 91.8 & 151.3 & 1.886 & 2.2 & 0.77 \\
\hline
\end{tabular}

\subsection{Heat Storage Cycle Experimental Device}

In order to test the feasibility of MNH90 for heat storage, a small-scale heat storage unit was designed and manufactured. Figure 3 shows the heat storage device has two groups of stainless-steel (304 SS) coils as heat exchanger, the inner side of heat exchanger coils is water and the outer side is phase change material. The heat exchanger has 2 header pipes, 2 serpentine branch-pipe groups (20 layers) and the length of the two water channels is equal. The total mass of MNH90 is $700 \mathrm{~kg}$, and it fills $92 \%$ of the space between the inside of the heat storage tank and the outside of the pipeline. The outside surface of the heat storage tank is a layer of rock wool thermal insulation with an average thickness of $100 \mathrm{~mm}$ and an external steel sheets shell. The overall size of the heat storage device is $1788 \mathrm{~mm}$ (length) $\times 220 \mathrm{~mm}$ (width) $\times 1776 \mathrm{~mm}$ high. The designed heat storage capacity of the heat storage device is $70 \mathrm{kWh}$, and its designed working temperature range is $20-100{ }^{\circ} \mathrm{C}$, which is mainly aimed at the working temperature of building heating. The heat storage 
system is manufactured, assembled, and debugged in Henan Energy Storage Technology Co., Ltd. Cc (Pingdingshan, China).
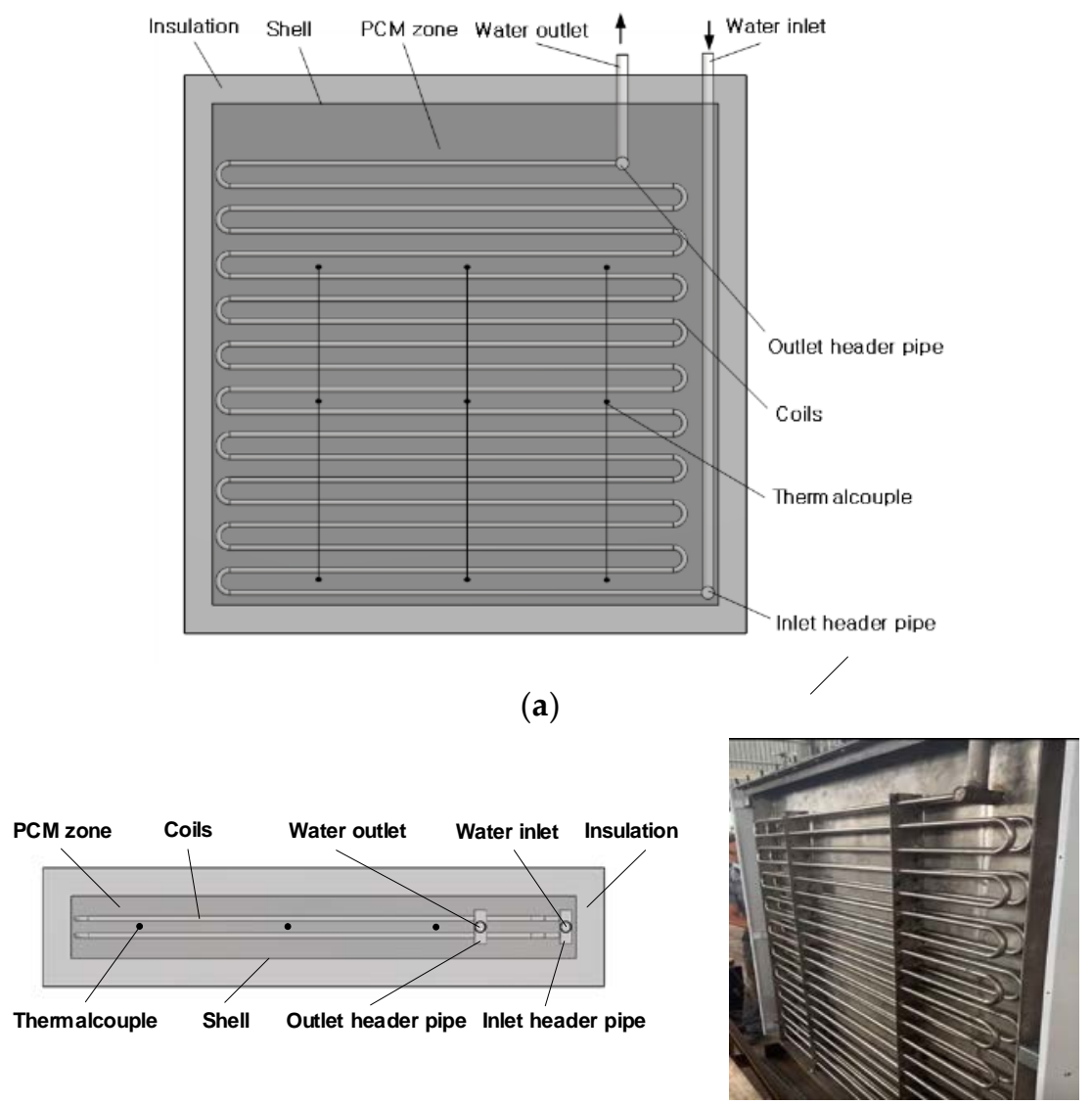

(b)

(c)

Figure 3. Heat storage device for MNH90 test: (a) plane section diagram, (b) vertical view, and (c) internal structure of heat storage.

\subsection{Testing System and Its Heat Performance Test}

A testing system was built to evaluate the charge and discharge capacity and cycling efficiency of MNH90. Figure 4a shows the system employs a hot water tank with $10 \mathrm{~kW}$ electric heater and a cold water tank with cooling coil to provide constant inlet temperature for the heat storage device. The heat transfer fluid for the heat storage device is water, and it was driven by a centrifugal water pump with a rated mass flowrate of $453 \mathrm{~kg} / \mathrm{h}$. The flow rate of water for heating or cooling is measured by an electromagnetic flowmeter. Total of 11 temperature measuring points, including the mean temperature of the water inlet (Tin) and water outlet (Tout), and the temperature of the MNH90 in the heat storage tank (between the two groups of coils, and the distance from the top of the tank inner surface are $498 \mathrm{~mm}, 1138 \mathrm{~mm}$ and $1618 \mathrm{~mm}$ ) are arranged to present the temperature in charging and discharging. Figure $4 \mathrm{~b}$ presents the full view of the experiment system. It is needed to mention that the current design of the heat storage device is a modular design. By means of series and parallel multiple such modules, it is easy to realize the amplification application of the phase change heat storage unit. The ambient temperature around the experimental system ranges from $23^{\circ} \mathrm{C}$ to $25^{\circ} \mathrm{C}$. 


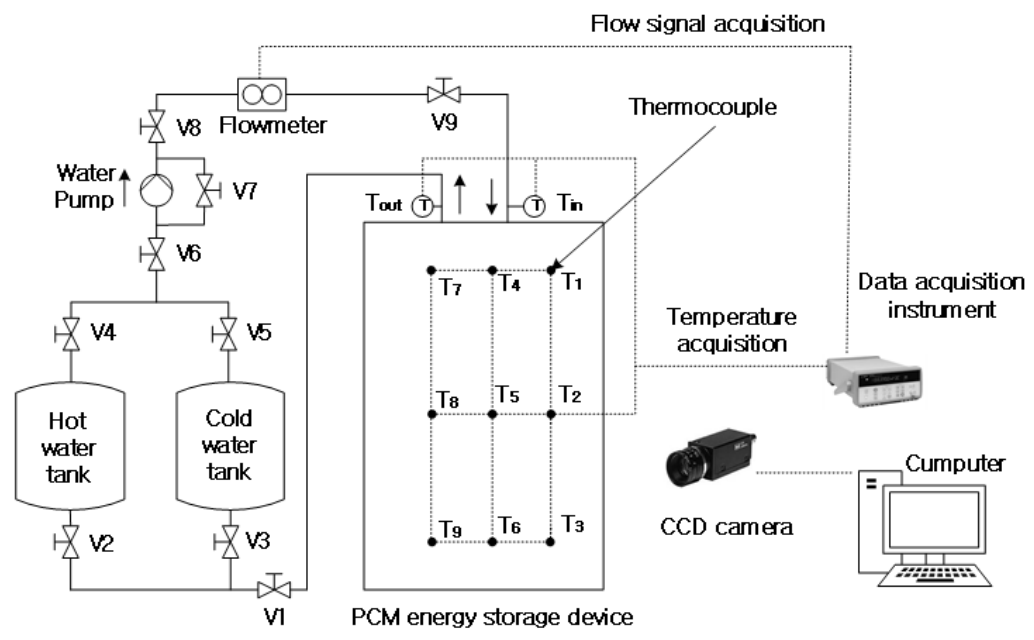

(a)

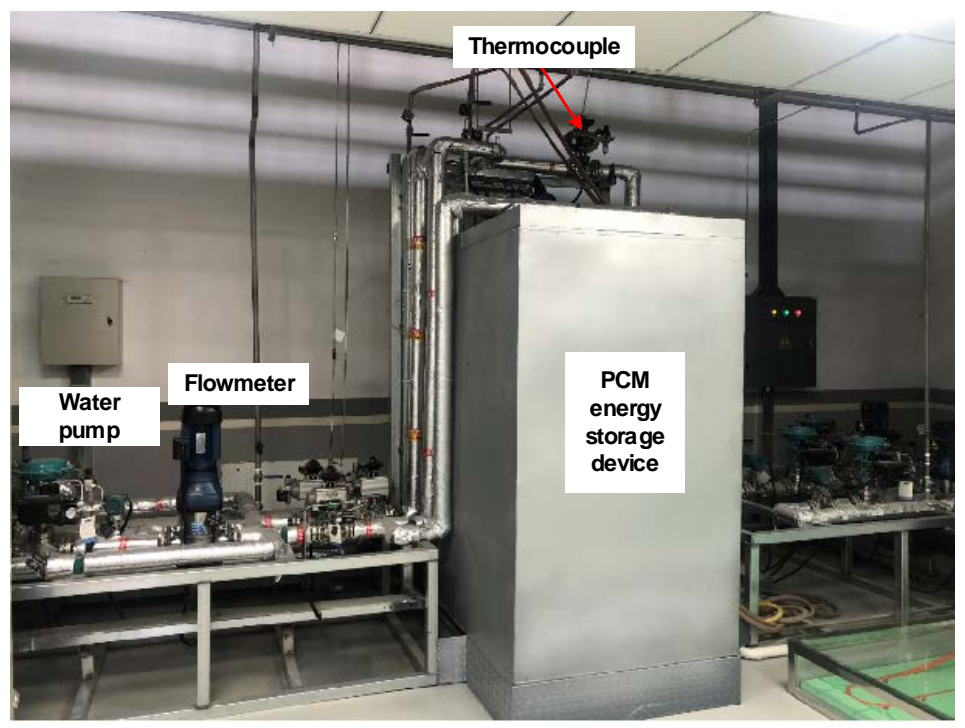

(b)

Figure 4. Performance test system of heat storage device: (a) schematic the experimental system and (b) the full view.

The detailed system operation strategy and test steps of this experiment are as follows: During the charging process, the electric heater is set to a constant thermal output with a given maximum outlet water temperature of $99.5 \pm 0.5^{\circ} \mathrm{C}$. When the average difference of mean water temperature between water inlet and water outlet drops below $3.0{ }^{\circ} \mathrm{C}$, heat charging stops. During heat discharging, the electric heater is shut down and the cooling water from cold water tank with the temperature of $20.5 \pm 0.5^{\circ} \mathrm{C}$ flows through the heat storage tank. When the temperature of outlet water drops below the given cut-off temperature of $38.5 \pm 0.5^{\circ} \mathrm{C}$, heat discharging is terminated. In this experiment, data acquisition instrument (34970A, Keysight) is used for automatic data acquisition, and the data acquisition interval is $10 \mathrm{~s}$.

\subsection{Performance Evaluation}

The heat storage capacity of MNH90 can be obtained by this equation [25]:

$$
Q=m \int_{T_{\min }}^{T_{\max }} c_{P, P C M} d T
$$


where $m$ is the total mass of MNH90, $T_{\min }$ and $T_{\max }$ are the start and end temperature of the MNH90 during charging process, and $c_{P}$ is the specific heat capacity of the MNH90.

The operating thermal power of the heat storage unit named as $P$ can be calculated by Equation (2), $T_{\text {in }}$ is the mean temperature of water inlet, $T_{\text {out }}$ is the mean temperature of water outlet, $\dot{m}$ is the mass flow rate of water, $c_{P, \text { water }}$ is the temperature-dependent specific heat capacity (using the mean temperature of $T_{\text {in }}$ and $T_{\text {out }}$ ) of water.

$$
P=\dot{m} c_{P, w a t e r}\left(T_{\text {in }}-T_{\text {out }}\right)
$$

The charging and discharging capacity of the heat storage device can be listed by the transient operating thermal power calculated by Equation (3):

$$
\left\{\begin{array}{l}
Q_{C}=\int_{t}^{t+t_{c}} P d t \\
Q_{D C}=\int_{t}^{t+t_{D C}} P d t
\end{array}\right.
$$

where $t_{C}$ and $t_{D C}$ are the time in heat charging and heat discharging procession, respectively. The cycling efficiency of charging and discharging (also be defined as the thermal efficiency) of the heat storage unit, which can show the energy storage and reuse efficiency of the heat storage device, can be defined as the ratio between $Q_{D C}$ and $Q_{C}$ :

$$
\eta=\frac{Q_{D C}}{Q_{C}} \times 100 \%
$$

The storage capacity factor $f$ which reflects the utilization of the heat storage capacity of the phase change heat storage device can be defined as the ratio of $Q_{C}$ and $Q$ :

$$
f=\frac{Q_{C}}{Q} \times 100 \%
$$

The heat loss of the phase change heat storage device can be calculated by Equation (6):

$$
Q_{\text {loss }}=\frac{A_{\text {surf }}\left(T_{P C M}-T_{a m b}\right)}{\frac{1}{h}+\frac{\delta_{\text {ins }}}{\lambda_{\text {ins }}}}
$$

where $T_{P C M}$ is the mean temperature of the MNH90 within the heat storage tank. $T_{a m b}$ is the room temperature. $h$ is the coefficient of natural convective heat transfer, assigned to $10 \mathrm{~W} /\left(\mathrm{m}^{2} \cdot \mathrm{K}\right)$ in this work. $\delta_{\text {ins }}$ is the thickness of the thermal insulation layer and the thermal conductivity $\lambda_{\text {ins }}$ is $0.05 \mathrm{~W} /(\mathrm{m} \cdot \mathrm{K})$. $A_{\text {surf }}$ is the surface area of the phase change heat storage device.

\subsection{Uncertainty Analysis of the Research Results}

The measurement ranges and measurement accuracy of the main detectors and instruments used in this research are listed in Table 2. The aluminum crucible which is used in the DSC analyzer can work above $300{ }^{\circ} \mathrm{C}$. It is calibrated with indium at the heating rate of $10 \mathrm{~K} / \mathrm{min}$ through the standard calibration procedure. The uncertainty for latent heat measurements is around $0.34 \%$, and the uncertainty for melting temperature is around $0.14 \%$. The Hot Disk analyzer is only suitable for experiments at room temperature. The measurement accuracy of electromagnetic flowmeter comes from the manufacturer's manual. The temperature sensors are A-grade PT-100 thermal resistance with external armors for inlet and outlet water temperature measurements, and K-type thermocouples for MNH90 temperature tests in the heat storage tank. 
Table 2. Information of the main detectors and instruments.

\begin{tabular}{cll}
\hline Instruments & \multicolumn{1}{c}{ Measurement Ranges } & \multicolumn{1}{c}{ Accuracy } \\
\hline & Room temperature to $750{ }^{\circ} \mathrm{C}$ & \\
& Heating rate: $0.1^{\circ} \mathrm{C} / \mathrm{min}$ to & $\pm 0.1{ }^{\circ} \mathrm{C}$ for temperature \\
& $50{ }^{\circ} \mathrm{C} / \mathrm{min}$ & sensor \\
DSC214 & Cooling rate: & $\pm 2 \%$ for calorimeter \\
& $0.1^{\circ} \mathrm{C} / \mathrm{min}$ to $2{ }^{\circ} \mathrm{C} / \mathrm{min}\left(<30{ }^{\circ} \mathrm{C}\right)$ & \\
& $0.1{ }^{\circ} \mathrm{C} / \mathrm{min}$ to $10^{\circ} \mathrm{C} / \mathrm{min}\left(\geq 30{ }^{\circ} \mathrm{C}\right)$ & $\pm 5 \%$ \\
Hot Disk TPS2500S & $0.005 \mathrm{~W} / \mathrm{m} \cdot \mathrm{K}$ to $500 \mathrm{~W} / \mathrm{m} \cdot \mathrm{K}$ & $\pm 1.5^{\circ} \mathrm{C}$ \\
K type thermocouple & $-40{ }^{\circ} \mathrm{C}$ to $375^{\circ} \mathrm{C}$ & $\pm 0.004|t|$ \\
PT-100 & $375^{\circ} \mathrm{C}$ to $1000^{\circ} \mathrm{C}$ & $\pm(0.15+0.002|t|)$ \\
Flowmeter & $-100-400{ }^{\circ} \mathrm{C}$ & $\pm 0.5 \%$ \\
\hline
\end{tabular}

Through the linear regression calculation of the temperature difference between the water temperature measured at the typical temperature point of the high-precision constant temperature water bath (the temperature control accuracy is $\pm 0.01{ }^{\circ} \mathrm{C}$ ), the measurement error introduced by the external armor and cable of the sensors were corrected by $50-120^{\circ} \mathrm{C}$ (the temperature interval is $10^{\circ} \mathrm{C}$ ). The uncertainty of key parameters of instruments and equipment involved in this study can be estimated according to the basic uncertainty in the list.

\section{Results and Discussion}

Figure 5 demonstrates the temperature evolution of key measuring points of the phase change heat storage device. About 800 cycles of heat charging and heat discharging were performed. Figure 5 a shows the temperature variations of water inlet and water outlet, the filled phase change material MNH90 during the first heat charging and discharging operation. Figure $5 \mathrm{~b}$ illustrates the measurement results after 800 cycles. The temperature difference between the mean temperature of MNH90 and the mean temperature of outlet water is also showed in Figure 5. It can be found that the entire charge and discharge cycle can be divided into six stages according to the temperature evolution of water and MNH90. Stages I, II, and III are charging phases and detected by whether the temperature of outlet water reaches the desired charging temperature, while stages IV, V, and VI are discharging phases and marked by whether the temperature of outlet water reaches the desired charging temperature. Stage I is sensible heat storage. MNH90 in this stage is pure solid, with the continuous heating by high-temperature inlet water, solid MNH90 and outlet water temperature increase rapidly, and the outlet water temperature is about 2 to 4 degrees higher than that of MNH90. When the MNH90 working temperature exceeds $90{ }^{\circ} \mathrm{C}$, the trend of temperature change slows down, and stage II can be regarded as the latent heat storage stage as the change of temperature tends to be gentle. In stage III, the water outlet temperature and MNH90 have obvious temperature jump, indicating that MNH90 is in the stage of sensible heat storage of pure liquid, further heating the results in a significant temperature rise. Stage IV is a transition stage, where the heat charging process ends and the heat discharging process starts. At a specific time, the outlet temperature of water is equal to the MNH90 temperature. Stage V is the phase change process in heat discharging, and $\mathrm{MNH} 90$ changes from liquid phase to solid phase and releases latent heat. In stage VI, MNH90 is already in the solid, and depends on the solid heat conduction to exchange heat with the water in the coil. 


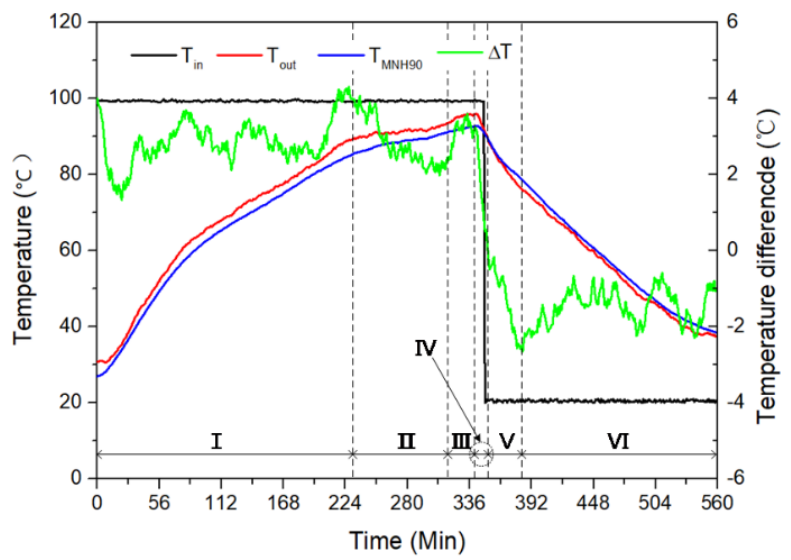

(a)

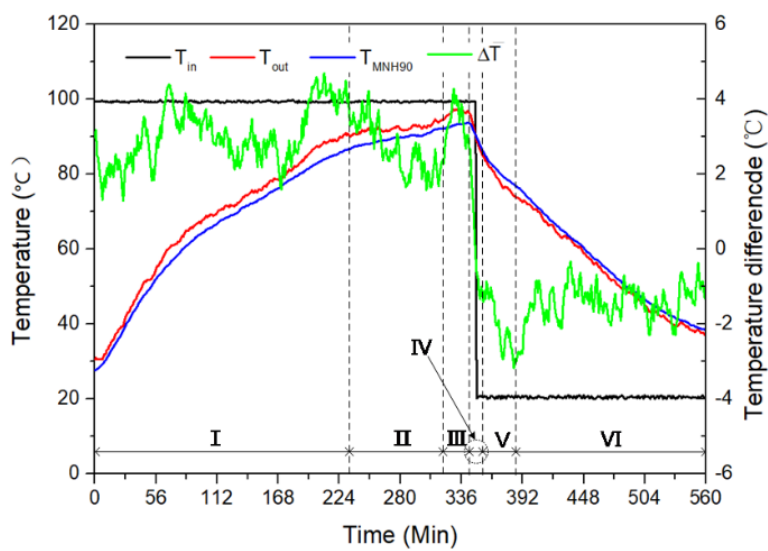

(b)

Figure 5. Temperature evolution of key measuring points of the phase change heat storage device (a) within the first typical charge-discharge operation (b) within the 800th typical charge-discharge operation.

Discharging performance and heat storage efficiency have always been the most concerned problems in the designing of a heat storage device. Figure 6 shows the discharging performance and heat storage efficiency of the small scale latent heat storage unit during the 800 cycles. The high efficiency of heat storage benefits from the thick insulation layer and rapid charging and discharging. However, it can still be seen that after 800 cycles of charging and discharging, the heat storage capacity of the heat storage device still has a slight decline, and it drops from $70.4 \mathrm{kWh}$ to $69.1 \mathrm{kWh}$, the heat storage performance decreases about $1.8 \%$. When the output temperature is customized according to different application scenarios, this phase change heat storage device with the maximum heat storage temperature of $110{ }^{\circ} \mathrm{C}$ is still much higher than that of atmospheric water storage device. 


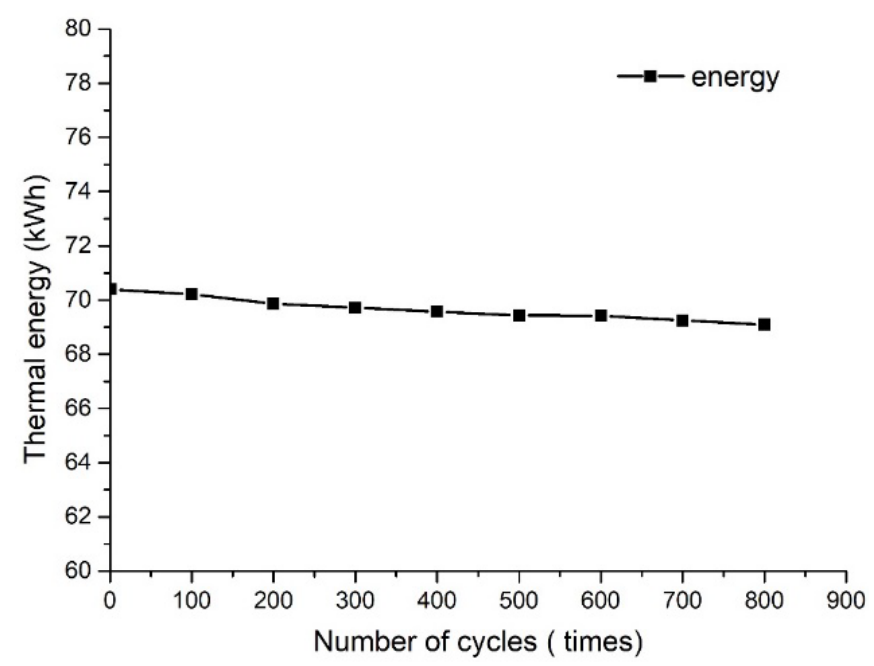

Figure 6. Discharging performance and heat storage efficiency during 800 cycles.

\section{Conclusions}

Using the salt hydrates as PCM is a promising method to replace the traditional atmospheric hot water heat storage. In this paper, the feasibility of a new developed phase change material named MNH90 is analyzed by the characterization of main thermophysical parameters and the experimental cycling performance study of heat charging and discharging. The main research conclusions received through the experiment can be listed as:

(1) The specific heat capacity of MNH90 at $20{ }^{\circ} \mathrm{C}$ is $1.6 \mathrm{~J} / \mathrm{g} \cdot \mathrm{K}$, and it increases slowly with the increase of temperature. When the temperature rises to $120^{\circ} \mathrm{C}$, the specific heat capacity reaches $4.1 \mathrm{~J} / \mathrm{g} \cdot \mathrm{K}$.

(2) The melting point of the material is $91.8^{\circ} \mathrm{C}$, the latent heat of phase change is $151.3 \mathrm{~J} / \mathrm{g}$, and in the cooling stage, the solidification temperature of the material is about $68^{\circ} \mathrm{C}$.

(3) The heat storage density of MNH90 is about $420 \mathrm{MJ} / \mathrm{m}^{3}$, which is about 2.5 times of that of water, assuming the temperature difference is $40^{\circ} \mathrm{C}$.

(4) With thick insulation layer, quick heat charging and heat discharging control method, the heat storage system can get a higher performance. The cycling test shows that the heat storage capacity decreases with the increase of cycle times, and the heat storage performance decreases about $1.8 \%$ after 800 operation cycles.

In conclusion, this paper proves the main thermophysical properties of MNH90 and its feasibility as a low temperature heat storage medium by experiments, and reveals the operation characteristics of MNH90 phase change heat storage equipment, which can provide some valuable information for the industrialization of this technology.

Author Contributions: Methodology, Y.F.; investigation, C.W.; data curation, J.Z.; writing-original draft preparation, Y.L.; writing - review and editing, J.M.; project administration, Y.F.; funding acquisition, J.M. All authors have read and agreed to the published version of the manuscript.

Funding: This research was funded by State Power Investment Corporation Central Research Institute of China, grant number B-ZY05-201803 and the National Natural Science Foundation of China under Grants, grant number 51827810, 51977193.

Conflicts of Interest: The authors declare no conflict of interest.

\section{References}

1. Emiliano, B.; Gabriel, Z.; Luisa, F.C. Recent developments of thermal energy storage applications in the built environment: A bibliometric analysis and systematic review. Appl. Therm. Eng. 2021, 189, 116666.

2. Ouhaibi, S.; Gounni, A.; Belouaggadia, N.; Ezzine, M.; Lbibb, R. Thermal performance of new ecological material integrated into residential building in semi-arid and cold climates. Appl. Therm. Eng. 2020, 181, 115933. [CrossRef]

3. Chang, C.; Wu, Z.; Navarro, H.; Li, C.; Leng, G.; Li, X.; Yang, M.; Wang, Z.; Ding, Y. Comparative study of the transient natural convection in an underground water pit thermal storage. Appl. Energy 2017, 208, 1162-1173. [CrossRef] 
4. Leng, G.; Qiao, G.; Jiang, Z.; Xu, G.; Qin, Y.; Chang, C.; Ding, Y. Micro encapsulated \& form-stable phase change materials for high temperature thermal energy storage. Appl. Energy 2018, 217, 212-220.

5. Xiong, Y.X.; Wang, Z.Y.; Wu, Y.T.; Xu, P.; Ding, Y.L.; Chang, C.; Ma, C.F. Performance enhancement of bromide salt by nano-particle dispersion for high-temperature heat pipes in concentrated solar power plants. Appl. Energy 2019, 237, 171-179. [CrossRef]

6. Chang, C.; Sciacovelli, A.; Wu, Z.; Li, X.; Li, Y.; Zhao, M.; Deng, J.; Wang, Z.; Ding, Y. Enhanced heat transfer in a parabolic trough solar receiver by inserting rods and using molten salt as heat transfer fluid. Appl. Energy 2018, 220, 337-350. [CrossRef]

7. Xu, Q.; Feng, J.; Liu, L.; Zhou, J.; Ye, G.; Chang, C. Analysis of mechanical-fluid-thermal performance of heat pipeline system with structural deformation effects. Int. J. Heat Mass Transf. 2019, 128, 12-23. [CrossRef]

8. Li, C.; Li, Q.; Cong, L.; Jiang, F.; Zhao, Y.Q.; Liu, C.P.; Xiong, Y.X.; Chang, C.; Ding, Y.L. MgO based composite phase change materials for thermal energy storage: The effects of $\mathrm{MgO}$ particle density and size on microstructural characteristics as well as thermophysical and mechanical properties. Appl. Energy 2019, 250, 81-91. [CrossRef]

9. Xu, Q.; Liu, L.; Feng, J.; Qiao, L.; Yu, C.; Shi, W.; Ding, C.; Zang, Y.; Chang, C.; Xiong, Y.; et al. A comparative investigation on the effect of different nanofluids on the thermal performance of two-phase closed thermosyphon. Int. J. Heat Mass Transf. 2020, 149, 119189. [CrossRef]

10. Zhao, B.C.; Wang, R.Z. Perspectives for short-term thermal energy storage using salt hydrates for building heating. Energy 2019, 189, 116-139. [CrossRef]

11. Lin, Y.; Alva, G.; Fang, G. Review on thermal performances and applications of thermal energy storage systems with inorganic phase change materials. Energy 2018, 165, 685-708. [CrossRef]

12. Ling, Z.; Li, S.; Zhang, Z.; Fang, X.; Gao, X.; Xu, T. A shape-stabilized $\mathrm{MgCl}_{2} \cdot 6 \mathrm{H}_{2} \mathrm{O}-\mathrm{Mg}\left(\mathrm{NO}_{3}\right)_{2} \cdot 6 \mathrm{H}_{2} \mathrm{O} /$ expanded graphite composite phase change material with high thermal conductivity and stability. J. Appl. Electrochem. 2018, 48, 1131-1138. [CrossRef]

13. Morimoto, T.; Sugiyama, M.; Kumano, H. Experimental study of heat transfer characteristics of phase change material emulsions in a horizontal circular tube. Appl. Therm. Eng. 2021, 188, 116634. [CrossRef]

14. McKenna, P.; Turner, W.J.N.; Finn, D.P. Thermal energy storage using phase change material: Analysis of partial tank charging and discharging on system performance in a building cooling application. Appl. Therm. Eng. 2021, 198, 198-117437. [CrossRef]

15. Lane, G.A. Phase change materials for energy storage nucleation to prevent supercooling. Sol. Energy Mater. Sol. Cells 1992, 27, 135-160. [CrossRef]

16. Wang, H.; Zhang, Y.; Ci, E.D.; Li, X.Q.; Li, J.Q. An experimental study in full spectra of solar-driven magnesium nitrate hexahydrate/graphene composite phase change materials for solar thermal storage applications. J. Energy Storage 2021, $38,102536$. [CrossRef]

17. Zhang, M.H.; Chen, X.; Dong, H. A study on multistep thermal decomposition behavior and kinetics of magnesium nitrate hydrate. Thermochim. Acta 2021, 701, 178951. [CrossRef]

18. Neeraj, G.; Amit, K.; Hrishikesh, D.; Avshish, K.; Abhishek, V.; Prashant, S.; Jain, V.K. Effect of shape and size of carbon materials on the thermophysical properties of magnesium nitrate hexahydrate for solar thermal energy storage applications. J. Energy Storage 2021, 41, 102899.

19. Honcova, P.; Pilar, R.; Danielik, V.; Soska, P.; Sadovska, G.; Honc, D. Suppressing supercooling in magnesium nitrate hexahydrate and evaluating corrosion of aluminium alloy container for latent heat storage application. J. Therm. Anal. Calorim. 2017, 129, 1573-1581. [CrossRef]

20. Honcova, P.; Sádovská, G.; Pastvová, J.; Kotál, P.; Seidel, J.; Sazama, P.; Pila, R. Improvement of thermal energy accumulation by incorporation of carbon nanomaterial into magnesium chloride hexahydrate and magnesium nitrate hexahydrate. Renew. Energy 2021, 168, 1015-1026. [CrossRef]

21. Nagano, K.; Ogawa, K.; Mochida, T.; Hayashi, K.; Ogoshi, H. Thermal characteristics of magnesium nitrate hexahydrate and magnesium chloride hexahydrate mixture as a phase change material for effective utilization of urban waste heat. Appl. Therm. Eng. 2004, 24, 221-232. [CrossRef]

22. Li, T.X.; Xu, J.X.; Wu, D.L.; He, F.; Wang, R.Z. High energy-density and power-density thermal storage prototype with hydrated salt for hot water and space heating. Appl. Energy 2019, 248, 406-414. [CrossRef]

23. Zhao, B.C.; Li, T.X.; He, F.; Gao, J.C.; Wang, R.Z. Demonstration of $\mathrm{Mg}\left(\mathrm{NO}_{3}\right)_{2} \cdot 6 \mathrm{H}_{2} \mathrm{O}$-based composite phase change material for practical-scale medium-low temperature thermal energy storage. Energy 2020, 201, 117711. [CrossRef]

24. Zhao, B.C.; Li, T.X.; Gao, J.C.; Wang, R.Z. Latent heat thermal storage using salt hydrates for distributed building heating: A multi-level scale-up research. Renew. Sustain. Energy Rev. 2020, 121, 109712. [CrossRef]

25. Rohsenow, W.M.; Hartnett, J.P.; Cho, Y.I. Handbook of Heat Transfer; McGraw-Hill: New York, NY, USA, 1998. 